\title{
Flow Reversal of Fully Developed Mixed Convection in a Vertical Channel with Chemical Reaction
}

\author{
Habibis Saleh, ${ }^{1}$ Ishak Hashim, $^{1,2}$ and Sri Basriati ${ }^{3}$ \\ ${ }^{1}$ School of Mathematical Sciences, Universiti Kebangsaan Malaysia, 43600 Bangi, Selangor, Malaysia \\ ${ }^{2}$ Solar Energy Research Institute, Universiti Kebangsaan Malaysia, 43600 Bangi, Selangor, Malaysia \\ ${ }^{3}$ Mathematics Sciences, UIN Sultan Syarif Kasim Riau, Panam, Pekanbaru 28293, Indonesia \\ Correspondence should be addressed to Habibis Saleh; dr.habibissaleh@gmail.com
}

Received 12 March 2013; Accepted 21 April 2013

Academic Editor: Donald L. Feke

Copyright (C) 2013 Habibis Saleh et al. This is an open access article distributed under the Creative Commons Attribution License, which permits unrestricted use, distribution, and reproduction in any medium, provided the original work is properly cited.

\begin{abstract}
The present analysis is concerned with the criteria for the onset of flow reversal of the fully developed mixed convection in a vertical channel under the effect of the chemical reaction. The governing equations and the critical values of the buoyancy force are solved and calculated numerically via MAPLE. Parameter zones for the occurrence of reversed flow are presented. The exothermic chemical reaction is found to enhance the flow reversal and made flow reversal possible for symmetrical walls temperature.
\end{abstract}

\section{Introduction}

The study of combined and free convection flow in a heated vertical parallel-plate channel has received considerable attention because of its wide range of applications such as geothermal reservoir, cooling of nuclear reactors, thermal insulation, energy storage, and conservation, chemical, food, and metallurgical industries, and petroleum reservoirs. A combined forced and natural convective flow puts on the situation where an externally driven flow joins with an native buoyant flow and when both are prominent. One of the earliest studies on mixed convection in a vertical channel with uniform wall temperatures had been studied analytically by Tao [1]. Then Habchi and Acharya [2] studied mixed convection in a vertical channel with asymmetric walls heating, where one plate is heated and the other is adiabatic. Fully developed flow was revisited by Aung and Worku [3] and Cheng et al. [4]. They analyzed effects of various boundary conditions and different constant temperature parameters on buoyancy-aided flow. Recently, Pop et al. [5] studied the mixed convection in a vertical channel with chemical reaction and found that dual solutions exist for both velocity and temperature.

The high buoyancy force due to a differentially heated wall combined with an upward flow leads to a high fluid flow adjacent to the walls that can precipitate a downward flow (i.e., reversal flow) emanating from the open top of the channel in order to augment the increased upward flow. Experiment on the appearance of flow reversal was conducted by Sparrow et al. [6] for free convection in a one-sided heated vertical channel. Aung and Worku [3] and Cheng et al. [4] studied analytically the occurrence flow reversal for the mixed convection. Criteria for the onset of flow reversal in terms of the Grashof to Reynolds number ratio were developed. Criteria for the occurrence of this flow, adjacent to the colder wall under effects of concentration, and magnetic field including internal heating, micropolar as well as thermophoretic, were presented by [7-9] and [10, 11], respectively.

Numerical studies by Pop et al. [5] found that reversed flow also occurs near the hot wall, where physically it is not possible [3]. They demonstrated that increasing the internal heating and constant temperature parameters could enhance the reversed flow but overlooked determining the criteria for the onset of flow reversal. Therefore, in this paper, we shall present the conditions for the onset of flow reversal of the fully developed flow mixed convection flow in a vertical channel under effect of the chemical reaction for various values of the constant temperature parameters studied by Pop et al. [5]. 


\section{Mathematical Formulation}

Consider the steady flow of a viscous and incompressible fluid between two vertical and parallel plane walls. The distance between the walls, that is, the channel width, is $\ell$. A coordinate system is chosen such that the $x$-axis is parallel to the gravitational acceleration vector $\mathbf{g}$, but with the opposite direction. The $y$-axis is orthogonal to the channel walls, and the origin of the axes is such that the positions of the channel walls are $y=0$ and $y=\ell$, respectively. A sketch of the system and of the coordinate axes is reported in Figure 1. The walls at $y=0$ and $y=\ell$ are isothermal at given temperatures $T_{1}$ and $T_{2}$, where we assume that $T_{1} \geq T_{2}$. The fluid has a uniform vertical upward stream wise velocity distribution $U_{0}$ at the channel entrance. Thus, the basic equations for steady, fully developed flow of a viscous, incompressible fluid and the heat assumed supplied to the surrounding fluid by an exothermic surface reaction [5] are

$$
\begin{gathered}
g \beta\left(T-T_{0}\right)-\frac{1}{\rho} \frac{d p}{d x}+\nu \frac{d^{2} u}{d y^{2}}=0, \\
\alpha \frac{d^{2} T}{d y^{2}}+Q k_{0} a e^{-E / R T}=0,
\end{gathered}
$$

subject to the boundary conditions:

$$
\begin{gathered}
u(0)=0, \quad u(\ell)=0, \\
T(0)=T_{1}, \quad T(\ell)=T_{2}, \quad\left(T_{1} \geq T_{2}\right) .
\end{gathered}
$$

Reaction takes place only on the surface which is governed by the single first-order Arrhenius kinetics. The closure system by mass flux conservation $M$ is $\int_{0}^{L} U d Y=M$. The dimensionless governing equations for the problem are [5]

$$
\begin{gathered}
\frac{d^{2} U}{d Y^{2}}=-G_{R} \Theta+A, \\
\frac{d^{2} \Theta}{d Y^{2}}=-K_{F} e^{\Theta},
\end{gathered}
$$

subject to the boundary conditions:

$$
\begin{gathered}
U(0)=0, \quad U(1)=0, \\
\Theta(0)=R_{T}, \quad \Theta(1)=-R_{T} .
\end{gathered}
$$

And the global conservation of mass at any cross section in the channel is $\int_{0}^{1} U d Y=1$.

\section{Solutions Method}

Equations (3) and (4) subject to (2) have been solved numerically by Pop et al. [5] using the $b v p p 4 c$ function from MATLAB. Pop et al. [5] found the solutions are possible only for the finite range of $K_{F}$. The range depend on constant temperature parameter, $R_{T}$, for example, at $R_{T}=1$, the solution domain are in $0 \leq K_{F}<3.155$. We solved again (3) and (4) subject to (5) via dsolve from MAPLE. The nonlinearities of (4) were handled by applying continuation, optional in dsolve. The continuation is utilized to maintain Newton method (inside package dsolve) reaching the convergence.

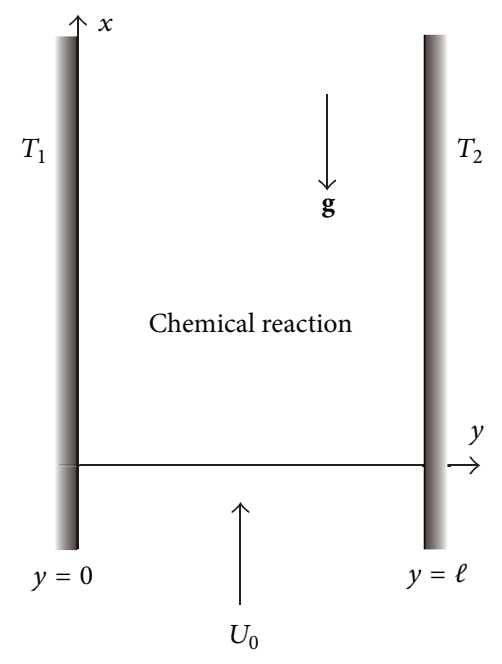

FIGURE 1: Schematic representation of the model.

\section{Results and Discussion}

The effects of various levels $G_{R}, K_{F}$, and $R_{T}$ are presented in Figure 2. These figures show that velocity increases as $G_{R}, K_{F}$, or $R_{T}$ increase. Flow reversal is found near the colder wall $(Y=1)$ for $G_{R} \geq 50$. Increasing the FrankKamenetskii number or constant temperature parameter enhances the flow reversal. The interesting behavior of the reversed flow occurs at $R_{T}=0.1$ in Figure 2(c), where reversal is found near both of the walls. This phenomenon due to heat generated by exothermic surface reaction and being conducted away into the surrounding fluid and this behavior progress continuously cause the rate of the increase in the temperature to rise sharply in middle region of the channel.

The result in Figure 2 also implies that there exists a critical value $G_{R c}$ such that, for $G_{R}>G_{R c}$, flow reversal occurs at $Y=1$. By setting $d U / d Y=0$ at $Y=1$ and utilizing dsolve with continuation, the $G_{R c}$ can be obtained within the solution domain. The numerical value $G_{R c}$ is plotted in Figure 3 .

It was observed that increasing the Frank-Kamenetskii number reduces $G_{R c}$ (Figure 3(a)), while reducing the temperature difference ratio increases the $G_{R c}$ (Figure 3(b)). When $K_{F}=0$, we recovered the critical value which had been calculated by Aung and Worku [3], Cheng et al. [4], El-Din [7], Barletta [12], and Chamkha et al. [9]. We can not obtain the critical value of the ratio of Grashof number and Reynolds number $\left(G_{R}\right)$ with symmetrical wall temperatures $R_{T}=0$ when there is no chemical reaction in the fluid. The $G_{R c}$ exists only in the range of constant $R_{T} \leq 0.05$.

\section{Conclusions}

Parameter zones for the occurrences flow reversal by mixed convection under the effect of chemical reaction in a vertical parallel-plate channel are presented. We can conclude that flow reversal adjacent to the cold wall is found to exist within the channel as the ratio of Grashof number and Reynolds number is above a threshold value. The exothermic chemical 


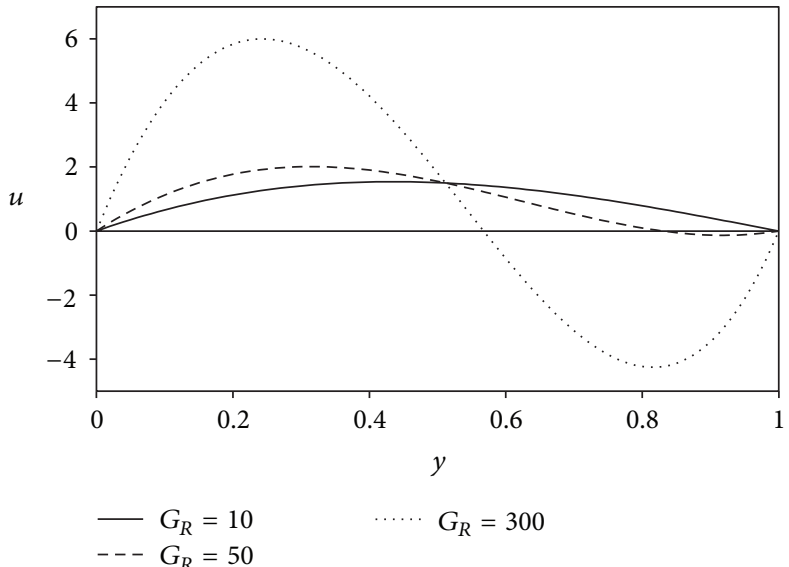

(a)
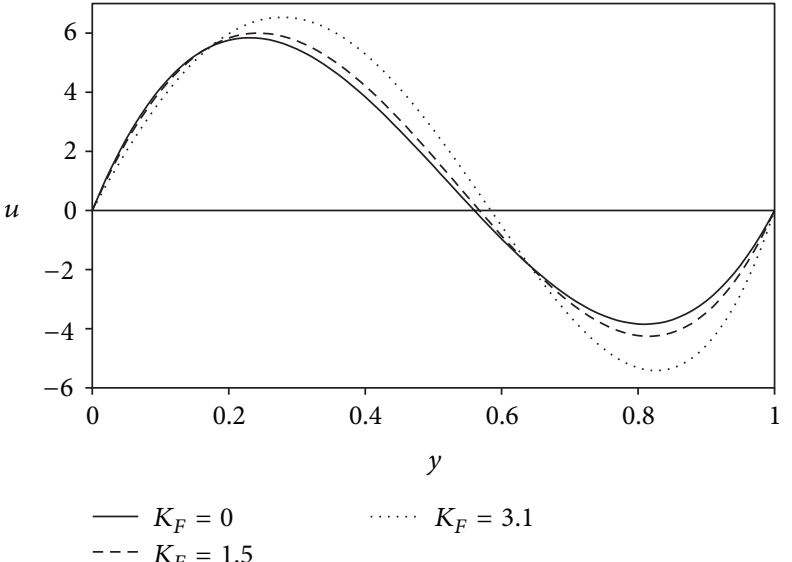

(b)

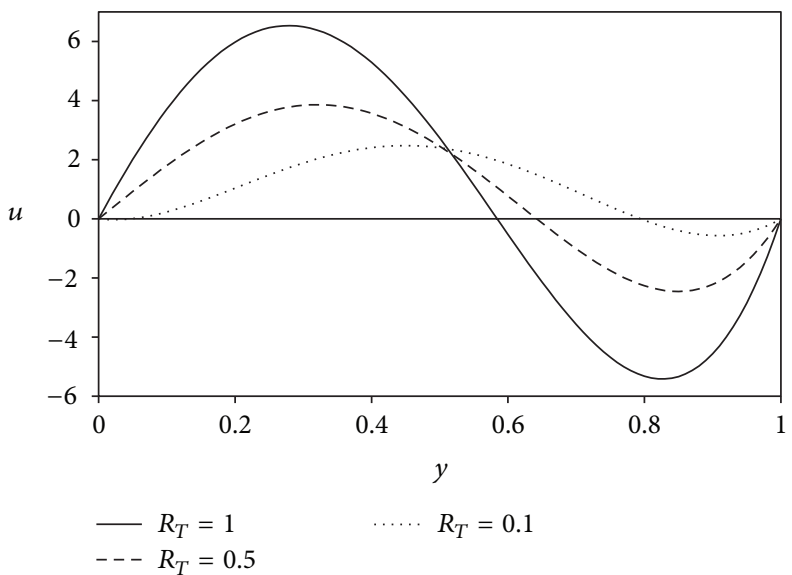

(c)

Figure 2: Plots of $U$ versus $Y$ for different values of (a) $G_{R}$ where $K_{F}=1.5, R_{T}=1$ (b) $K_{F}$ where $G_{R}=300, R_{T}=1$, and (c) $R_{T}$ where $G_{R}=300, K_{F}=3.1$.

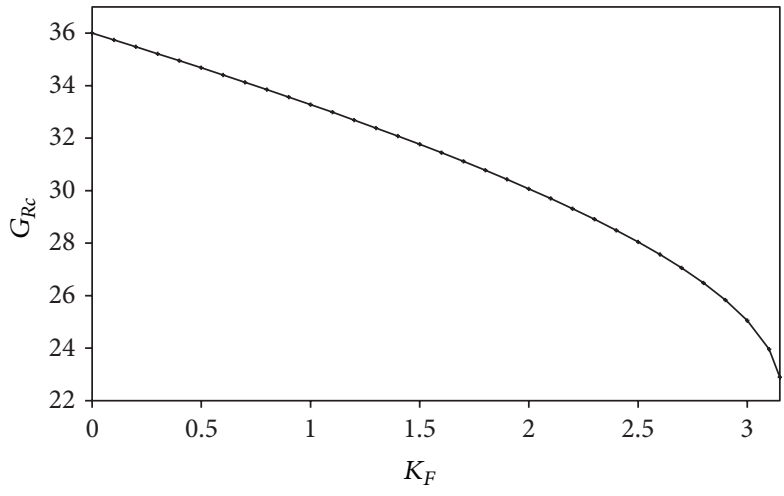

(a)

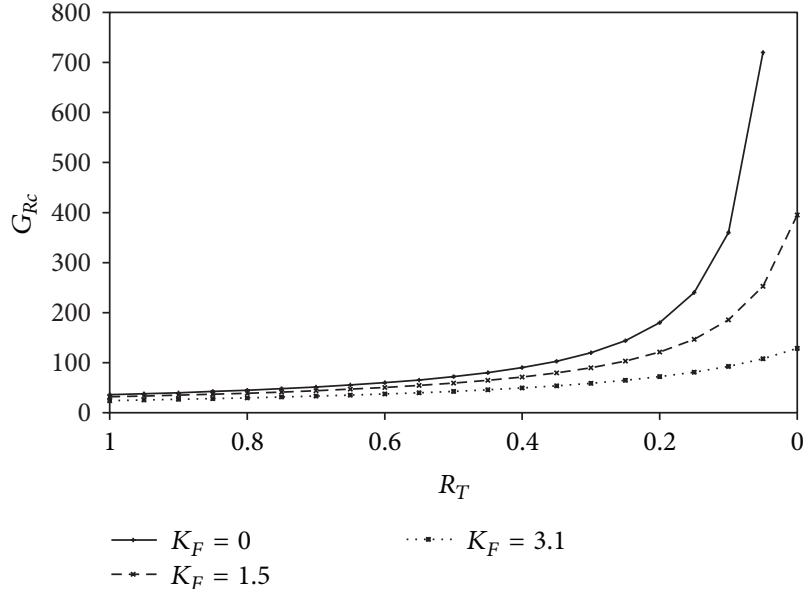

(b)

Figure 3: The critical value $G_{R c}$ for the onset of a flow reversal with (a) increasing $K_{F}$ and (b) reducing $R_{T}$. 
reaction is found to enhance the flow reversal and made flow reversal possible for symmetrical walls temperatures. The aspect of the nonuniqueness of the solution as found by Pop et al. [5] will be the focus of our next research undertaking.

\section{Nomenclature}

$\begin{array}{ll}a: & \text { Concentration of reactant } \\ A: & \text { Axial pressure gradient, } d p / d x \\ \mathrm{Gr}: & \text { Grashof number } \\ G_{R}: & \text { Dimensionless parameter, Gr/ Re } \\ g: & \text { Gravitational acceleration } \\ E: & \text { Activation energy } \\ k_{0}: & \text { Preexponential factor } \\ K_{F}: & \text { Frank-Kamenetskii number } \\ \ell: & \text { Channel width } \\ Q: & \text { Exothermicity factor } \\ R: & \text { Universal gas constant } \\ \text { Re: } & \text { Reynolds number } \\ R_{T}: & \text { Temperature difference ratio } \\ T: & \text { Temperature } \\ U: & \text { Dimensionless velocity components in } \\ & \text { the } x \text {-direction } \\ X, Y: & \text { Dimensionless space coordinates. }\end{array}$

$X, Y$ : Dimensionless space coordinates.

\section{Greek Symbols}

$\alpha$ : Thermal diffusivity

$\beta$ : Thermal expansion coefficient

$\rho$ : Density

$\Theta$ : Dimensionless temperature

$\mu$ : Dynamic viscosity

v: Kinematic viscosity.

\section{Subscript}

0 : Reference value

1: Left wall

2: Right wall

c: Critical.

\section{References}

[1] L. N. Tao, "On combined free and forced convection in channels," Journal of Heat Transfer, vol. 82, pp. 233-238, 1960.

[2] S. Habchi and S. Acharya, "Laminar mixed convection in a symmetrically or asymmetrically heated vertical channel," Numerical Heat Transfer A, vol. 9, no. 5, pp. 605-618, 1986.

[3] W. Aung and G. Worku, "Theory of fully developed, combined convection including flow reversal," Journal of Heat Transfer, vol. 108, pp. 299-304, 1986.

[4] C. H. Cheng, H. S. Kou, and W. H. Huang, "Flow reversal and heat transfer of fully developed mixed convection in vertical channels," Journal of Thermophysics and Heat Transfer, vol. 4, no. 3, pp. 375-383, 1990.

[5] I. Pop, T. Grosan, and R. Cornelia, "Effect of heat generated by an exothermic reaction on the fully developed mixed convection flow in a vertical channel," Communications in Nonlinear Science and Numerical Simulation, vol. 15, no. 3, pp. 471-474, 2010.
[6] E. M. Sparrow, G. M. Chrysler, and L. F. Azevedo, "Observed flow reversals and measuredpredicted nusselt numbers for natural convection in a one-sided heated vertical channel," Journal of Heat Transfer, vol. 106, no. 2, pp. 325-332, 1984.

[7] M. M. S. El-Din, "Fully developed forced convection in a vertical channel with combined buoyancy forces," International Communications in Heat and Mass Transfer, vol. 19, no. 2, pp. 239-248, 1992.

[8] A. J. Chamkha, "On laminar hydromagnetic mixed convection flow in a vertical channel with symmetric and asymmetric wall heating conditions," International Journal of Heat and Mass Transfer, vol. 45, no. 12, pp. 2509-2525, 2002.

[9] A. J. Chamkha, T. Groşan, and I. Pop, "Fully developed mixed convection of a micropolar fluid in a vertical channel," International Journal of Fluid Mechanics Research, vol. 30, no. 3, pp. 251-263, 2003.

[10] T. Grosan, R. Pop, and I. Pop, “Thermophoretic deposition of particles in fully developed mixed convection flow in a parallelplate vertical channel," Heat and Mass Transfer, vol. 45, no. 4, pp. 503-509, 2009.

[11] E. Magyari, "Thermophoretic deposition of particles in fully developed mixed convection flow in a parallel-plate vertical channel: the full analytical solution," Heat and Mass Transfer, vol. 45, no. 11, pp. 1473-1482, 2009.

[12] A. Barletta, "Laminar mixed convection with viscous dissipation in a vertical channel," International Journal of Heat and Mass Transfer, vol. 41, no. 22, pp. 3501-3513, 1998. 

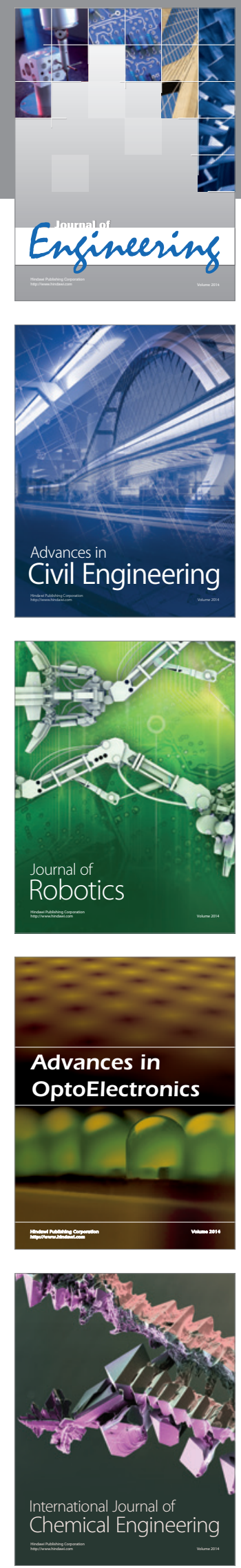

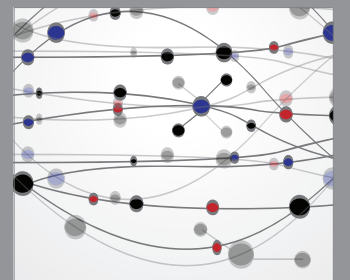

The Scientific World Journal
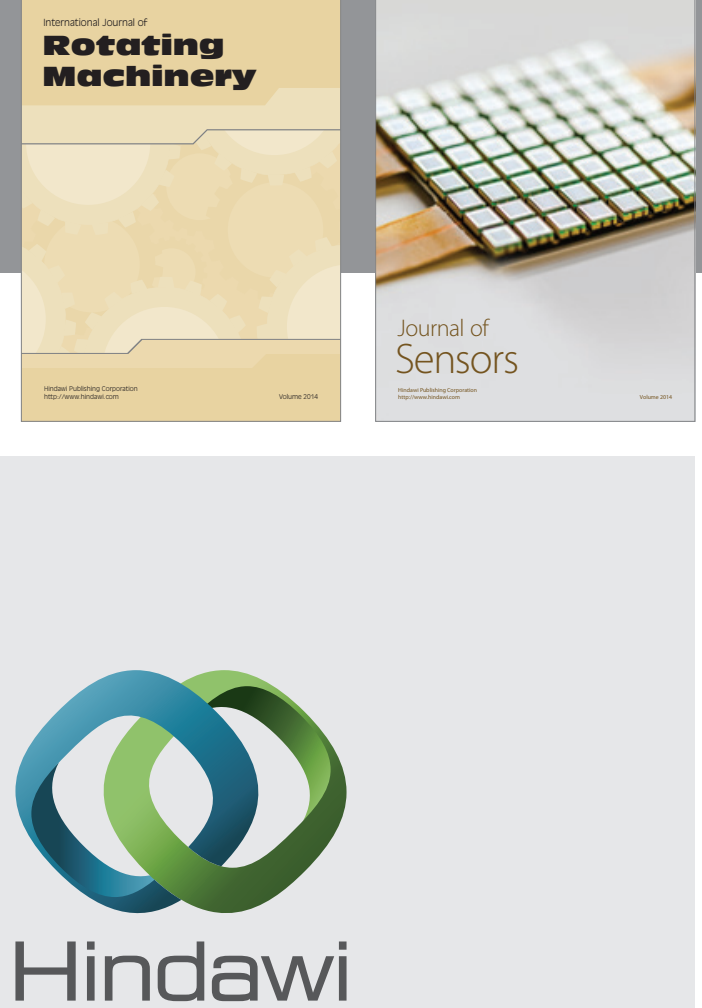

Submit your manuscripts at http://www.hindawi.com

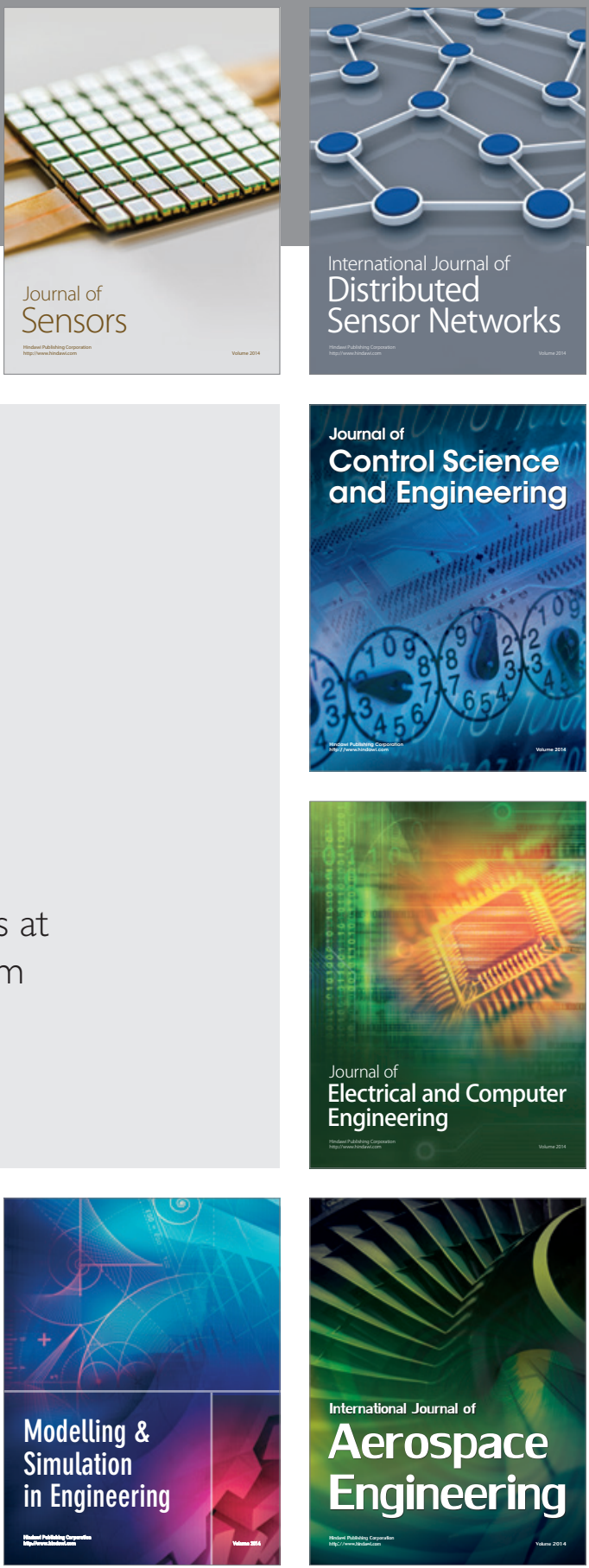

Journal of

Control Science

and Engineering
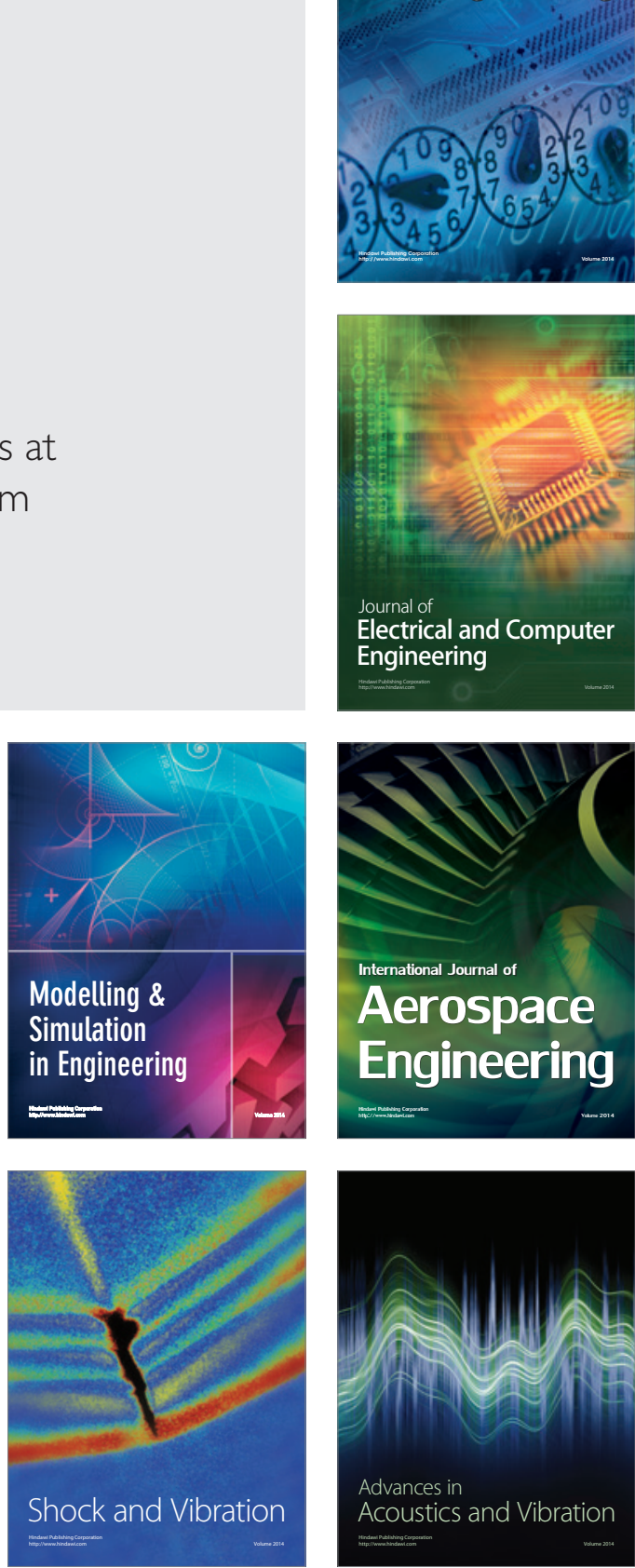